\title{
Research on the Impact of E-commerce on Enterprise Performance Based Factor Analysis
}

\author{
Xiong $\mathrm{Hu}$ \\ Tangshan College, Tangshan 063000, Hebei, China \\ *Corresponding author: Xiong Hu (303308208@qq.com)
}

\begin{abstract}
In recent years, e-commerce has become one of the most active areas of scientific development, and more and more enterprises begin to build their own e-commerce platform. In this paper, we research the E-commerce capabilities by using factor analysis method; the result shows that electronic commerce can significantly improve enterprise performance. In this process, compound human resources, partner resources and information sharing will strengthen the role of e-commerce. In the era of e-commerce, enterprises can not only pay attention to their own business, the most important is to integrate their partners and resources, and only in this way enterprise be more competitive in market and to achieve win-win.
\end{abstract}

Keywords: Enterprise Performance; Cooperative process; E-commerce; Partner resources

\section{Introduction}

In recent years, e-commerce has become one of the most active areas of scientific development, more and more enterprises in building their own e-commerce platform, enterprises with e-commerce to carry out new business activities, strengthen cooperation between enterprises. Information technology has become one of the most active fields of scientific development. It not only makes the innovation of traditional industries, but also promotes the development of production and promotes the competitive advantage of enterprises. Technology has gradually been recognized and used, along with the integration of technology and modern business enterprise management has changed from the past throughout the product design, production, sales, service and other business processes, development has become a business cooperation and the same step process, in the process of achieving collaboration between enterprises in the process of e-commerce has played a vital role in [1]. Electronic commerce comes from the technology, but it is different from the general technology, because the electronic commerce in addition to the advantages of high efficiency and information in the network, it emphasizes the combination of technology and management ideas, highlighting the cooperation between enterprises. In the era of e-commerce, enterprises can not only pay attention to their own and other enterprises to compete with other companies, but through the electronic commerce will own and partner resources together, through the construction of ecommerce platform, and then form a kind of cooperation between enterprises and ecommerce capabilities, and only in this way can be in the increasingly competitive market and partners to achieve win-win [2]. The impact of Electronic Commerce on the enterprise is not only reflected in the form of corporate sales update, but also marks the strategic level of the enterprise has shifted from the past single access to market competitive advantage to achieve common benefits through cooperation with partners. It will involve the collaboration between enterprises and partners, through the rational allocation of resources, integrated enterprise internal and external application, and thus 
improve the ability to handle the inter organizational process, improve customer demand response.

Therefore, the impact of electronic commerce, not only in the form of enterprise market sales update, but also marks the strategic level of the enterprise from the past single access to market competition advantage to achieve common benefits through cooperation with partners. Electronic commerce will be involved in the cooperation between the business partners, the reasonable allocation of the supply chain enterprise resources, the integration of various applications, and the parallel operation of the enterprise. How to integrate internal and external resources and the ability to use this ability in the enterprise has become a hot spot in the development and research of enterprise e-commerce.

\section{Literature Review}

E-commerce originated in the last century sixty's technology, but it is different from the technology in addition to the inherent characteristics of information exchange, more significant is the emphasis on technology and management of electronic commerce. This combination can penetrate into every aspect of the enterprise, e-commerce is a prominent place is to emphasize the cooperation between enterprises, however, in the traditional manufacturing enterprises or supply chain enterprises tend to see information on the degree of confidentiality, which to a certain extent, affect the process of cooperation between enterprises [3]. If the enterprise in the daily production and business activities too much emphasis on the protection of information, communication between enterprises will encounter obstacles, information island is widespread, the cooperation between the enterprises have a certain impact. Enterprises in the supply chain can make the whole supply chain cannot make a comprehensive and rapid response to the market demand, and ultimately lead to a decline in customer satisfaction, corporate profits will also decline. So the impact of electronic commerce is not only reflected in the form of enterprise market sales update, but also in the strategic level of the enterprise from the past single access to market competition advantage to achieve common benefits through cooperation with partners. E-Commerce is also involved in the coordination of business partners, the rational allocation of supply chain enterprise resources, and the application of integrated enterprise. Better realize the parallel operation of the enterprise. How to integrate internal and external resources and the ability to use this ability in the enterprise has become a hot spot in the development and research of enterprise e-commerce.

\subsection{Enterprise Cooperation in E-commerce}

With the development of the society, the traditional boundary of the enterprise is becoming more and more blurred. When exchanging information between enterprises penetrates to a certain extent, companies often do not know the value generated from the location. The research on the electronic commerce based organization is relatively small, which is mainly concentrated in the supply chain. Zuo (2013) considers that the different attributes of enterprise products and services determine the basis of the customer's choice of suppliers. The choice of inter enterprise e-commerce in supply chain is mainly concentrated in the cost of the transaction and the delivery of the convenience and speed of [4]. Shoki (2012) through the study of the electronic business cooperation between the major buyers and suppliers, the electronic information sharing and electronic business cooperation is the important factor of the formation of the enterprise's e-commerce capabilities [5]. 
Liem (2013) research is the main problem of information sharing between enterprises. He believes that the enterprise should want to do real information sharing not only within the enterprise, but also to establish a good sharing mechanism between enterprises, these mechanisms are a relationship of mutual trust, mutual encouragement [6]. At the same time, information sharing behavior is also influenced by the perceived benefits and costs. The research and comparison of the domestic enterprises' cooperation in the electronic commerce, the research focus is not the same as Li Jie's research is mainly in the inter enterprise partnership. From the supply chain, the risk benefit risk, legal risk, the cooperation between enterprises should strengthen internal control and external control Chen Changbin, etc., they take the information sharing in the supply chain cooperation as the key point. The key is to establish effective information sharing incentive mechanism. At present, there is no fixed pattern in the research of domestic and foreign research. This article is to want through the electronic commerce in the supply chain in the information exchange, information sharing and integration of resources between enterprises to form the cooperation between enterprises and e-commerce. Djelassi (2013) et al.'s research that the impact on the enterprise cooperation is not due to its technical ability, but only with the interaction between the interaction of the enterprise to promote cooperation between enterprises. Their research uses trust, dependence, and information sharing and other dimensions to measure the relationship between firms [7].

Since the last century, e-commerce has been confronted with the confusion of the application of electronic commerce. The relationship between the enterprise and the benefit of the enterprise is the first time to study the relationship between enterprise performance and enterprise performance. Sharma (2014) firstly put forward the relationship between the capability and enterprise performance. A high ability of enterprises through self configuration can produce significant organizational performance [8]. Ramanathan (2012) considered as a kind of enterprise resources, if the management of the enterprise can make the right guidance and use, will have a positive impact on the performance of the enterprise. They developed the concept of competence and pointed out that the effect of organizational learning decision on the performance of [9].

\subsection{Information Technology Capability}

In order to obtain the operating profit for the survival basis of enterprises, in addition to providing quality products and services, but also to pay close attention to their own business environment and competitive environment. As the top managers of the enterprise, information management should be regarded as the object of its own, and it is also necessary to realize that only the enterprise has the ability of continuous development of management information to make the enterprise obtain sustainable competitiveness, so as to stabilize the market, bring good performance for the enterprise.

Gebauer (2012) first proposed the concept of ability, he through the enterprise practice research that the enterprise obtains the competitive advantage is not from facilities, but ability, he put the ability into human resources, technical facilities and business partners. And on the basis of this, he regarded his ability as a kind of ability to control and related costs and the use of the influence of organizational strategy [10]. Sinem (2013) first proposed the relationship between capability and enterprise performance. Along with the research, the scholars often take one kind of industry as their own research object to elaborate own to understand [11]. Manjit (2013) the study of the financial services industry as the research object, using the method of language and case study to study the classification of ability. The research shows that the construction of the difference is reflected in a continuous 
process, which is based on the ability, and the ability to merge into four main attributes, which include the system size, system focus, system can be and the level of integration. Doina (2014) to explore the reasons why a large amount of investment and investment in the enterprise has not achieved the desired results, he developed the concept of ability and pointed out the effect of organizational learning decision on the performance of the. Many scholars more recognition of information technology can be used as an effective means of competition, and whether it can bring about a sustained competitive advantage for the enterprise [12].

View Resource-based is a research field of information system in the middle of 1990s. RVB is to study the ability of IT from the perspective of resource theory, through the study of how to build and obtain a kind of IT capability, and it can make the enterprise obtain the long-term advantage in the application of information technology. Doin (2014) was the first to be considered as a resource. It can be divided into three kinds of physical capital, human capital and organizational capital resources [13]. Ahmad (2012) proposed a business transformation model based on the research results show that the enterprise can adjust the company's internal resources and capabilities, including enterprise business processes, technologies and suppliers and partnerships, and then generate a high-level resources, the authors say, online information capability". Zakuan (2014) proposed the integration of resource based theory and other viewpoints, proposed the business value integration model, and pointed out that the resources through the embedded enterprise business process, and then produce process performance and organizational performance. However, the resources and the ability to separate, he believes that the resource is the enterprise in the production process through a input. Such inputs include human resources, capital and technology, and the ability to perform a task or activity in the use of one or more resources in the use of a resource. Along with the research, the difference between the ability and the resources is more and more clear. Kim (2014) considers that there is a kind of mutual transformation between resources and capabilities, and the business process is a kind of important intermediate control variables. In recent years, with the increasing number of e-commerce into the business process of the enterprise, some scholars directly to the electronic commerce as the research object [14].

\section{Research Model and Theoretical Hypothesis}

\subsection{Research Model}

This paper is based on the mechanism of the formation of inter firm cooperation in e-commerce, and discusses the impact of this capability on the performance of enterprises. The premise of this paper is to have a complete information system (IS) with their partners. In this chapter, we establish the research model, which is based on the research questions. These six variables are compound IT human resource (ITHR), organization partnership (OPR), internal e-commerce capabilities (IEC), partner information sharing ability (PISC), partner Process Capability (PTPC) and Enterprise performance (PE), respectively. Resource analysis refers to the three kinds of resources analysis, which is related to the IT. The information system can realize the integration of enterprise internal and external business information in order to support the business activities of enterprises. Enterprise information system is generally speaking, can be divided into the internal information system and external information system, in which the internal information system is the enterprise information sharing between departments and internal information system integration. The external information system includes the information sharing of the enterprise resource and the connection of the external information system 
equipment. In order to simplify the study of the model, it is assumed that the enterprise's internal and external information system is implemented, which is the enterprise's external information system, which can produce positive effect to the enterprise's internal information system, and they can have a positive effect on the formation of the internal electronic commerce. It is almost the core of the other dependent on the resources of the human resource. The most valuable is the compound type of human resources, it is in favor of the use of technology for all kinds of employees daily office management and organizational decision-making skills assessment.

In this paper, the ability of the variable is mainly refers to the enterprise's internal and external e - commerce capabilities. Internal electronic commerce capability is the ability of the organization in the process of implementing the electronic commerce process, through the enterprise's technology and network to realize the enterprise internal information sharing and process transformation. Enterprise external electronic commerce capability is mainly refers to the formation of the partnership and the formation of the shared information and cooperation process capability. E-commerce capabilities is disclosed in e-business processes in enterprise organizations the unique ability to integrate the formation of the resource, but also the core competitiveness of enterprises e-commerce. This research is based on the ability to form the basis of tracking the core competitiveness of enterprises to improve the performance of the way and the way.

\subsection{Research Hypothesis}

Enterprise organization performance is the ability of the enterprise, which mainly includes facilities and human resources, especially the human resources to the organization's performance has a very significant impact. The research on the enterprise is a better explanation of how the enterprise can form the core competitiveness of the enterprise, which is based on the organization ability, which includes the complex human resources, technology and information system. So we make the following assumptions

Hypothesis 1: compound human resources has a significant impact on the formation of the internal electronic commerce capability of enterprises

With the use of e-commerce in the enterprise, e-commerce in the enterprise logistics supply chain, so the cooperation between enterprises is becoming more and more closely, and the interaction between the core business and partnership is particularly important. In the enterprise internal system and electronic orders, electronic procurement, information retrieval, and information sharing between partners, to avoid redundant intermediate costs between enterprises, strengthen the transformation of the business process of the enterprise. Through empirical research, the main factors that explain the formation of enterprise network capacity, in addition to the integration of various resources in the enterprise, as well as the relationship between the electronic interaction and cooperation partners. Therefore, in the era of electronic commerce, the cooperation between enterprises is bound to affect the performance of the enterprise, the enterprise cooperation with the partnership will have an important role in the formation of sharing information and cooperation process capability. So we make the following assumptions

Hypothesis 2: partner resources have a significant impact on the formation of enterprise partner oriented collaborative process capability

Hypothesis 3: the ability to share information among enterprises has a significant impact on the formation of the cooperative process capability

The use of the Internet, the opportunity to cut a lot of cost, these costs are mainly some practical cost, communication costs, and through the network between enterprises can enhance trust, improve service opportunities, and optimize the 
business process of supply chain. The internal network of the enterprise is connected with the information system of each department, so the information share of the enterprise is realized. The external network is the way that the enterprise can transmit information to the outside, and the network can realize the information sharing in the supply chain. Once in the process of cooperation between enterprises, on the one hand, it will make the work to share more useful information resources, these resources through integration will generate a lot of potential business opportunities, these potential business opportunities will have a significant impact on the performance of the enterprise. So we make the following assumptions

Hypothesis 4: the ability of the business enterprise internal electronic commerce has a significant effect on the formation of the information ability of the partners

Hypothesis 5: the cooperation process capability of the partners has a significant effect on the enterprise performance

\section{Empirical Analysis}

\subsection{Research Design}

In this study, we analyze the collected data to verify the theoretical assumptions and models. This paper is based on the integration of resources in the enterprise and the enterprise. Through the cooperation between enterprises and enterprises to enhance the ability of sharing information between enterprises and partners, and ultimately, this ability is reflected in the performance of the enterprise. So we must design a reasonable questionnaire according to the research needs. Using the designed questionnaire survey, this research can be carried out through the field, and through the network survey, and the first hand data collected through the statistical software for further processing, to achieve our hypothesis and model validation.

The design of scale is a very important part of this research. Because of the accuracy of the scale and the "attraction", it will not only affect the validity of the questionnaire, but also affect the psychological perception of the people. According to the model and hypothesis of this research, the paper designs the questionnaire, which is based on the concept of information ability, cooperation ability, and enterprise performance. The main contents of the research include: the first part is the background of the implementation of the electronic commerce and the basic situation of the survey. Including the information of the company's name, size, the implementation of e-commerce time, e-commerce experience stage, object-oriented, the implementation process and the use of the system was investigated in the name of the staff, the position in the enterprise, working hours, etc.. This part of the main role is used to distinguish the true validity of the questionnaire. The second part is mainly based on the 6 variables of the study design of the questionnaire, the use of the common Likert five point scales, in the use of 1-5 to distinguish them. 1 means "do not agree ", 3 means "general agreement", 5 means "very agree". The basis of the questionnaire design is the past literature review and the current situation of the implementation of e-commerce in China, can be seen in Table 1.

Table 1. Variable Description of Indicators

\begin{tabular}{|c|c|c|}
\hline Variable & Index & Content \\
\hline $\begin{array}{c}\text { Compound } \\
\text { human } \\
\text { resources }\end{array}$ & Employee IT skills & Basic information technology skills \\
\cline { 2 - 3 } & Employee IT training & $\begin{array}{c}\text { Employees will be trained regularly in } \\
\text { information technology }\end{array}$ \\
\hline $\begin{array}{c}\text { Partner } \\
\text { resources }\end{array}$ & Cooperation mechanism & $\begin{array}{c}\text { Enterprises have established a cooperative } \\
\text { mechanism }\end{array}$ \\
\cline { 2 - 3 } & Benefit recognition & Cooperation between the two sides recognize \\
\hline
\end{tabular}




\begin{tabular}{|c|c|c|}
\hline \multirow{2}{*}{} & Technical ability & $\begin{array}{c}\text { the importance of the realization of the } \\
\text { interests }\end{array}$ \\
\cline { 2 - 3 } & Internal sharing & $\begin{array}{c}\text { Partners have the ability to carry out } \\
\text { electricity suppliers }\end{array}$ \\
\cline { 2 - 3 } $\begin{array}{c}\text { Enterprise E- } \\
\text { commerce } \\
\text { capability }\end{array}$ & Process improvement & $\begin{array}{c}\text { Enterprise according to needs, can carry out } \\
\text { process transformation }\end{array}$ \\
\hline $\begin{array}{c}\text { Shared } \\
\text { information }\end{array}$ & Procurement process & Information sharing on purchasing process \\
\cline { 2 - 3 } $\begin{array}{c}\text { Cooperative } \\
\text { process } \\
\text { capability }\end{array}$ & Order process & Information sharing in order process \\
\cline { 2 - 3 } & Partnership & Business and cooperation partners \\
\hline \multirow{2}{*}{$\begin{array}{c}\text { Enterprise } \\
\text { performance }\end{array}$} & Customer satisfaction & Customer satisfaction for business services \\
\cline { 2 - 3 } & Work efficiency & $\begin{array}{c}\text { Enterprise internal work efficiency } \\
\text { improvement }\end{array}$ \\
\cline { 2 - 3 } & Sales performance & Enterprise profit and market share increase \\
\hline
\end{tabular}

\subsection{The Questionnaire Survey}

The questionnaire of this study is based on the needs of the model and hypothesis. The questionnaire was selected from foreign mature scale, distributed and collected 490 valid questionnaires, the reliability of the questionnaire was analyzed, and the reliability coefficient was above, which showed that the design of the questionnaire had high reliability. Subsequently, according to the research progress, enterprise research in Tangshan City, through the manual release, telephone consultation, a variety of ways, such as manual payment, the purpose of this is to enter a different enterprise, to investigate the actual situation of the enterprise, contact with the social economy of the specific cell two is through field investigation, more perfect their research, in practice to guide scientific research. This investigation due to control is good, all kinds of channels to collect the questionnaire is generally more effective, a total of 600 questionnaires were collected, including the network asked 400 volumes, 200 copies of artificial. The specific situation of the questionnaire was shown in table 2 .

Table 2. Distribution of Sample Data

\begin{tabular}{|c|c|c|c|c|c|}
\hline $\begin{array}{l}\text { Charact } \\
\text { eristics }\end{array}$ & classification & number & $\begin{array}{c}\text { Percentage } \\
(\%)\end{array}$ & $\begin{array}{c}\text { Effective } \\
\text { percentage }\end{array}$ & $\begin{array}{l}\text { cumulative } \\
\text { percentage }\end{array}$ \\
\hline \multirow{2}{*}{ gender } & Male & 288 & 58.77 & 58.77 & 58.77 \\
\hline & female & 202 & 41.22 & 41.22 & 100 \\
\hline \multirow{4}{*}{ position } & Top managers & 35 & 7.14 & 7.14 & 7.14 \\
\hline & Middle managers & 98 & 20.0 & 20.0 & 27.14 \\
\hline & First-line managers & 103 & 21.02 & 20.02 & 47.16 \\
\hline & employees & 254 & 51.83 & 51.83 & 100 \\
\hline \multirow{4}{*}{ industry } & manufacturing & 53 & 10.81 & 10.81 & 10.81 \\
\hline & The computer & 120 & 24.48 & 24.48 & 35.29 \\
\hline & retail & 192 & 39.18 & 39.18 & 74.49 \\
\hline & The financial sector & 125 & 25.51 & 25.51 & 100 \\
\hline & total & 490 & 100 & 100 & 100 \\
\hline
\end{tabular}

\subsection{Reliability Test}

The reliability and validity of the test were derived from the concept of reliability and validity. These two very important technical indicators are often used in the construction and measurement. Reliability is reliability, which means the stability and consistency of 
the results of the questionnaire survey, namely, the measurement of the measurement of the instrument or the scale can be measured by using the same method. In this study, we refer to the majority of scholars used the crown of Baja. We generally believe that the reliability coefficient of the scale to reach 0.9 , it has excellent reliability, measurement reliability coefficient a if in 0.8 , in the academic community is generally considered acceptable if the coefficient is more than 0.7 , then we need to do some necessary changes to improve its consistency, otherwise the value is small, the most unsatisfactory situation is that the scale is a big problem, cannot use. On the basis of academic rigor, we have made the reliability test for all the variables to ensure the validity of our scale. Test results shows in table 3.

Table 3. Reliability Analysis of Variable

\begin{tabular}{|c|c|c|}
\hline Variable & Index & $\alpha$ coefficient value \\
\hline \multirow{2}{*}{ Complex human resources } & Employee IT skills & \multirow{2}{*}{0.873} \\
\hline & Employee IT training & \\
\hline \multirow{3}{*}{ Partner resources } & Cooperation mechanism & \multirow{3}{*}{0.886} \\
\hline & Benefit recognition & \\
\hline & Technical ability & \\
\hline \multirow{2}{*}{$\begin{array}{l}\text { Enterprise E- commerce } \\
\text { capability }\end{array}$} & Internal sharing & \multirow{2}{*}{0.765} \\
\hline & Process improvement & \\
\hline \multirow{2}{*}{ Shared information } & Procurement process & \multirow{2}{*}{0.837} \\
\hline & Order process & \\
\hline \multirow{2}{*}{ Cooperative process capability } & Partnership & \multirow{2}{*}{0.878} \\
\hline & Sales forecast & \\
\hline \multirow{3}{*}{ Enterprise performance } & Customer satisfaction & \multirow{3}{*}{0.891} \\
\hline & Work efficiency & \\
\hline & Sales performance & \\
\hline
\end{tabular}

Along with the thorough research, we found that the influence of the factors such as the scope of the investigation object is very close. As the reliability test is used in the form of correlation coefficient, if the characteristics of the object of the survey is larger, the greater the variability, the smaller the reliability coefficient. The reliability coefficient is larger; the length of questionnaire design is closely related to the reliability of the questionnaire, and the reliability of the questionnaire is higher than that of the same target and the same questionnaire, which is based on the two questionnaires. Through the reliability test, we found that the reliability of the performance of the enterprise reached 0.891 , the partners reached 0.886 , which showed that the reliability of these variables were shown to have good reliability. The reliability coefficient of the variable enterprise internal electronic commerce ability is 0.765 , according to the previous discussion, the coefficient is 0.7 , then we must make some necessary changes to the scale, to improve its consistency, the same can be accepted. To sum up the above analysis, we can think that the reliability of the scale is good, can carry out the validity analysis.

\subsection{Confirmatory Factor Analysis}

The validity of the test is generally difficult to construct validity, construct validity, content validity, criterion validity, etc.. The construct validity is the method of testing the validity of our study. The basic idea of factor analysis is to find the common factors in order to achieve the purpose of dimension reduction. Although EFA and CFA are associated with but they are in the basic idea, the application premise, the theoretical hypothesis, the analysis steps, and so on. The main difference between exploratory factor analysis and confirmatory factor analysis is whether the use of prior information is used in the process of seeking common factors. The exploratory factor analysis is based on the existing sample data, and uses the statistical software to analyze the process of the factors. 
The confirmatory factor analysis is based on the theory, which is based on the assumption that the structure of the prior hypothesis is that each factor is corresponding to a specific set of indicator variables, which is used to test whether the structure is consistent with the observed data. It is assumed that all the factors affect the measurement in a certain degree, but in the practical research, we assume that there is no causal relationship between the factors, so it is not affected by the other factors. Exploratory factor analysis also requires all the factors to be independent, but this is often inconsistent with the actual. And the thought of confirmatory factor analysis is to allow us to use a priori information, through the test of the validity of the measurement items and the design of the factors there is no significant load. In normal circumstances, the measures and the designed factors should have a very significant load, while the non relevant factors are not significant. We analyze the model of the measurement, and the results are shown in Table 4.

Table 4. Confirmatory Factor Analysis

\begin{tabular}{|c|c|c|c|}
\hline Variable & Index & Standard load & T value \\
\hline \multirow{2}{*}{ Compound human resources } & Employee IT skills & 0.73 & 10.21 \\
\cline { 2 - 4 } & Employee IT training & 0.76 & 11.45 \\
\hline \multirow{3}{*}{$\begin{array}{c}\text { Partner resources } \\
\text { Enterprise E-commerce } \\
\text { capability }\end{array}$} & Cooperation mechanism & 0.84 & 8.07 \\
\cline { 2 - 4 } & Benefit recognition & 0.86 & 7.35 \\
\cline { 2 - 4 } & Technical ability & 0.81 & 10.87 \\
\cline { 2 - 4 } Shared information & Internal sharing & 0.85 & 13.67 \\
\hline \multirow{2}{*}{$\begin{array}{c}\text { Cooperative process capability } \\
\text { Eny }\end{array}$} & Procurement process & 0.79 & 16.08 \\
\cline { 2 - 4 } & Order process & 0.74 & 12.31 \\
\cline { 2 - 4 } & Partnership & 0.78 & 6.28 \\
\hline \multirow{2}{*}{\begin{tabular}{c} 
Enterprise performance \\
\cline { 2 - 4 }
\end{tabular}} & Customer satisfaction & 0.72 & 8.24 \\
\cline { 2 - 4 } & Work efficiency & 0.80 & 4.78 \\
\cline { 2 - 4 } & Sales performance & 0.72 & 10.67 \\
\hline
\end{tabular}

Table 5. Correlation Matrix and AVE Value

\begin{tabular}{|c|c|c|c|c|c|c|}
\hline & IHR & OPT & IEC & PTSC & PTPC & OP \\
\hline IHR & 0.814 & & & & & \\
\hline OPT & 0.560 & 0.780 & & & & \\
\hline IEC & 0.387 & 0.467 & 0.724 & & & \\
\hline PTSC & 0.463 & 0.382 & 0.359 & 0.701 & & \\
\hline PTPC & 0.528 & 0.446 & 0.380 & 0.396 & 0.735 & \\
\hline OP & 0.358 & 0.262 & 0.424 & 0.455 & 0.359 & 0.750 \\
\hline
\end{tabular}

Factor analysis certificate path coefficients show the degree of influence the direction and influence of potential variables. In order to analyze the predictive ability of the model, we introduce the tooth to the extent endogenous variable is explained in front of potential variables. We tested for significant coefficients in front of each path, the results found by the road map: Partner Resources relation on information sharing is not significant, other studies assume substantially confirmed the results shown in Table 6 .

Table 6. Analysis of the Results of Path Coefficient

\begin{tabular}{|c|c|c|c|}
\hline Hypothesis & Coefficient & T value & Result \\
\hline Hypothesis 1 & 0.271 & 3.781 & accept \\
\hline Hypothesis 2 & 0.377 & 5.612 & accept \\
\hline Hypothesis 3 & 0.506 & 10.655 & accept \\
\hline Hypothesis 4 & 0.663 & 11.801 & accept \\
\hline Hypothesis 5 & 0.504 & 9.978 & accept \\
\hline
\end{tabular}


The research found that the compound human resources in the enterprise's internal and external electronic commerce ability plays an important role in the formation process, the enterprise should do is the integration of internal and external resources, this integration will require a combination of human resources to do security. In the process of the formation of the ability of the internal electronic commerce, the starting point of human resources, through cooperation with the IS, the internal resources integration, and thus the formation of internal electronic commerce. In this study, the compound human resources in the internal electronic commerce facilities with the cooperation, the ability of the internal electronic commerce has played a huge role in the formation. Composite human resources in the enterprise mainly by the enterprise staff's skills, enterprise staff training and participation in e-commerce will, through exploratory factor analysis we can see, these three indicators are very good description of human resources, the human resources, which plays a leading role.

\section{Conclusion}

This paper makes a thorough investigation on the actual situation of the enterprise implementation of e-commerce, using empirical research methods, analyzes the formation of the enterprise's electronic commerce cooperation ability to form the enterprise's performance: how the enterprise through the integration of internal and external IT resources, and realize the information sharing, and form the enterprise internal and external electronic commerce capabilities, in this ability to form and then into a kind of enterprise performance has a positive effect. The research results of this paper will play a strong role in the application of e-commerce.

The formation of inter-enterprise sector is the ability to share information outside the enterprise information system integration of resources and partnerships formed, and the ability to form collaborative process on this basis. The research found that the reason why the enterprise can form the external electronic commerce ability is because the enterprise information platform construction, relying solely on partner resources or a single construction enterprise external IS information system, cannot meet the needs of enterprise electronic business cooperation, also cannot form we need to share information on the resource relationship. In the daily business process, we have to build the information platform and business process interface, only in this way we can achieve the information exchange, for the next implementation of the electronic ordering and electronic procurement to do the groundwork. For cooperative enterprises: in the initial stage of cooperation, the cooperation between enterprises is mainly reflected in the information communication and transmission, but with the deepening of cooperation, the cooperation between enterprises is based on trust and benefit sharing.

\section{Acknowledgements}

We are grateful to the editors and anonymous reviewers for their valuable comments on this paper. The work of this paper is supported by Science and Technology Fund Project of Tangshan College (Grant No. 15012B)

\section{References}

[1] Y.Zhang, J.Bian, "Trust fraud: A crucial challenge for China's e-commerce market",Electronic Commerce Research and Applications, Vol. 12, No.5, (2013),pp.299-308.

[2] S.Samiee, "Global marketing effectiveness via alliances and electronic commerce in business-tobusiness markets",Industrial Marketing Management, Vol.37, No. 1, (2008), pp.3-8.

[3] S.Mohamad, U.Ahmad, "The Attributes of Electronic Service Quality (e-SQ) among Academic Librarians",Procedia - Social and Behavioral Sciences, Vol. 65, (2012), pp.260-265.

[4] W.Zuo, Q.Huang , "Quality management of B2C e-commerce service based on human factors engineering”,Electronic Commerce Research and Applications, Vol.12, (2013), pp.309-320. 
[5] M.Shoki, L.Yun, and N.Zakuan, "Examining Dimensions of Electronic Service Quality for Internet Banking Services",Procedia - Social and Behavioral Sciences, Vol.65, (2012), pp.854-859.

[6] V.Liem, and A.Cass, "Innovation and business success: The mediating role of customer participation",Journal of Business Research, Vol. 66, No. 8, (2013), pp.1134-1142.

[7] S.Djelassi, and I.Decoopman, "Customers' participation in product development through crowd sourcing: Issues and implications", Industrial Marketing Management, Vol.42, No.5, (2013), pp.683692.

[8] S.Sharma, and J.Conduit, "Organisational capabilities for customer participation in health care service innovation", Australasian Marketing Journal (AMJ), Vol.22, No. 3, (2014), pp.179-188.

[9] R. Ramanathan, U.Ramanathan, "The impact of e-commerce on Taiwanese SMEs: Marketing and operations effects", International Journal of Production Economics, Vol.140, No.2, (2012), pp. 934-943.

[10] H.Gebauer, M.Paiola, and B.Edvardsson, "A capability perspective on service business development in small and medium-sized suppliers", Scandinavian Journal of Management, Vol.28, No.4, (2012), pp.321-339.

[11] E.H.Sinem, and Z.Kabaday1, "Innovation Orientation, Market Orientation and e-Loyalty: Evidence from Turkish e-Commerce Customers", Procedia - Social and Behavioral Sciences, Vol.99, (2013), pp.509516.

[12] S.Manjit, and V.Kristine, "Social Commerce: A Contingency Framework for Assessing Marketing Potential",Journal of Interactive Marketing, Vol.27, (2013), pp.311-323.

[13] D.Doina, and C. Margea, "Electronic Services for Business Environment", Procedia - Social and Behavioral Sciences, Vol.124, (2014),pp.351-360.

[14] J. Lee, H.Kim, The willingness of e-Government service adoption by business users: The role of offline service quality and trust in technology", Government Information Quarterly, Vol.28, (2011), pp.222230. 
International Journal of Security and Its Applications

Vol.9, No.10 (2015) 